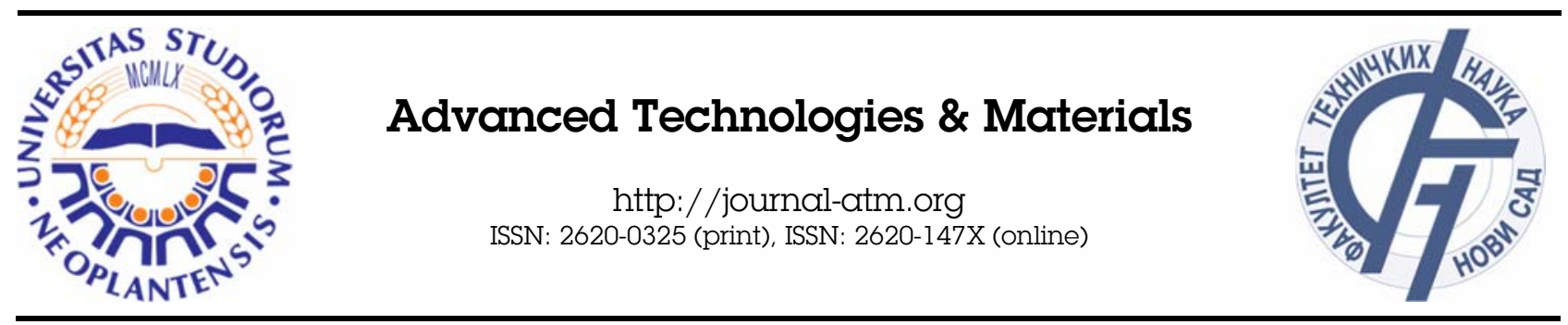

Original article

\title{
The influence of continuous casting technology on the cleanliness of carbon steel
}

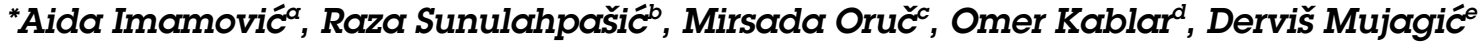 \\ a,b,c,d The Faculty of Metallurgy and Technology, University of Zenica \\ e Institute „Kemal Kapetanović", University of Zenica
}

\begin{abstract}
The influence of the production method, i.e. casting technology on the cleanliness and thus the quality of carbon steels is best determined through the presence and type of non-metallic inclusions. A large number of inclusions, especially oxide and complex ones, can significantly affect the mechanical properties of carbon steels and limit their application for the production of finished products.

This paper presents the influence of the presence, type and amount of non - metallic inclusions in B500B carbon steel according to ASTM / AISI produced by continuous casting technology without and with the application of stream protection.
\end{abstract}

Key words: carbon steel, continuous casting, non-metallic inclusions, stream protection

\section{INTRODUCTION}

The constant development and progress in science and technology places increasing demands for new and higher quality steels particularly in terms of mechanical properties. Therefore, today various measures are applied in order to produce "clean steel" and set ever-increasing requirements in terms of steel quality, which primarily include:

- lower content of impurities (sulphur, phosphorus, oxygen, nitrogen, hydrogen and other undesirable elements in steel),

- lower content of non-metallic inclusions,

- control of morphology, size and chemical composition of inclusions.

To meet these requirements, there are constant improvements in steel production technology, especially in the field of secondary metallurgy, such as the introduction of stream protection in continuous casting.

\subsection{Cleanliness of steel and non-metallic inclusions}

Non-metallic inclusions can be formed by the reaction of metals (e.g. iron, manganese, aluminum, etc.) and non- metals (e.g. oxygen, sulphur, nitrogen, carbon, etc.). Most inclusions in steel are oxides and sulphides.Oxides originate from deoxidation or are excreted during crystallization, and may also occur if the steel comes in contact with oxygen from the air (reoxidation). Sulphides are excreted during crystallization at the grain boundaries, because the solubility of sulphur in solid steel is lower than in liquid steel and they have an extremely detrimental effect on the properties of steel. If the inclusion contains more than one chemical compound such as e.g. various oxides and sulphides, are called complex inclusions (e.g. aluminosilicates, oxysulphides, carbonitrides, etc.).

Non-metallic inclusions play a very important role in the material properties, and have a great impact on the processing and application of steel products.

The origin and mechanical properties of non-metallic inclusions depend on the type of inclusions and their chemical composition, which is also reflected in the behavior of non-metallic inclusions during plastic deformation of steel castings, Fig. 1. [1]

During the casting of steel, there is a partial transfer of oxygen from the atmosphere into the open stream of liquid metal, which causes reoxidation and the formation of inclusions. This process depends on several factors

*Corresponding author's.e-mail: aida.imamovic@unze.ba 
such as the temperature of the liquid steel, the casting speed, the degree of deoxidation of the steel, etc. Steel reoxidation means an increase in the total oxygen content which is directly related to the reactivity of the elements dissolved in the steel in the presence of oxygen. Not only the number and size of inclusions but also their nature and morphology are important for the properties of steel.

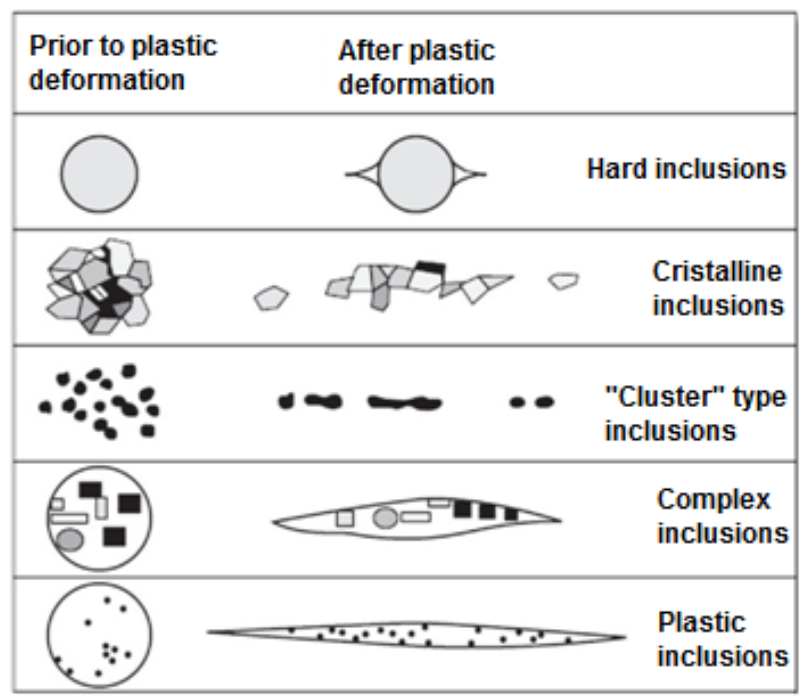

Fig. 1 Schematic representation of the behavior of non-metallic inclusions during plastic deformation depending on their relative plasticity at high temperatures [1]

During the casting of steel, there is a partial transfer of oxygen from the atmosphere into the open stream of liquid metal, which causes reoxidation and the formation of inclusions. This process depends on several factors such as the temperature of the liquid steel, the casting speed, the degree of deoxidation of the steel, etc. Steel reoxidation means an increase in the total oxygen content which is directly related to the reactivity of the elements dissolved in the steel in the presence of oxygen. Not only the number and size of inclusions but also their nature and morphology are important for the properties of steel.

With the introduction of ladle metallurgy, significant improvements have been achieved in terms of increasing the degree of cleanness, and to that end care is taken to protect liquid steel during casting to prevent the reaction of liquid steel with oxygen from the air.

Clean steel has a relatively lower content of harmful impurities and non-metallic inclusions, which can be achieved by controlling casting and preventing reoxidation, and is carried out using closed casting technology, i.e. by casting under the jet protection (SEN tundish) and with the application of inert gases, Fig. 2.

\section{PRACTICAL PART}

In order to produce steel with the highest possible degree of cleanness in terms of the content of non-metallic inclusions, ArcelorMittal Zenica has approached the improvement of existing casting technology by introducing closed casting technology and installing devices for stream protection type 13 QC.

In the practical part of the research, the influence of closed casting technology on the quality of carbon steel from the aspect of steel cleanness is presented. Testing of steel grade B500B samples was performed, ie samples of one melt cast by open casting technology and one melt cast by closed casting technology [3].

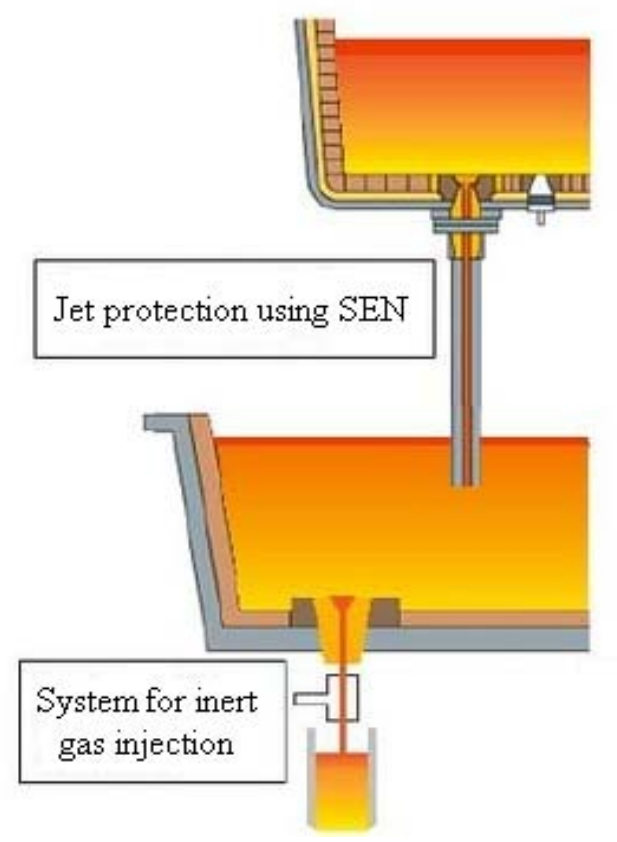

Fig. 2 Application of jet protection in the process of continuous steel casting [2]

\subsection{Types of low carbon steel quality samples}

To test the degree of cleanness of steel, ie to determine the number and size of non-metallic inclusions, four samples were used for melt cast by open casting technology, designated with B500B-OC, as well as for melt cast by closed casting technology, designated B500B-CC, whose chemical composition is shown in Table 1. [3].

Table 1 Chemical composition of tested steel melt designated B500B according to ASTM/AISI [3]

\begin{tabular}{|c|c|c|c|c|c|}
\hline \multirow{2}{*}{ B500B } & \multicolumn{5}{|c|}{ Chemical composition (\%) } \\
\cline { 2 - 6 } & $\mathrm{C}$ & $\mathrm{Si}$ & $\mathrm{Mn}$ & $\mathrm{P}$ & $\mathrm{S}$ \\
\hline $\begin{array}{c}\text { ASTM/ } \\
\text { AISI }\end{array}$ & 0.22 & - & - & 0.050 & 0.050 \\
\hline $\begin{array}{c}\text { B500B } \\
- \text { OC }\end{array}$ & 0.17 & 0.12 & 0.51 & 0.026 & 0.008 \\
\hline $\begin{array}{c}\text { B500B } \\
- \text { CC }\end{array}$ & 0.18 & 0.12 & 0.53 & 0.038 & 0.009 \\
\hline
\end{tabular}


Based on Table 1, it can be concluded that the prescribed chemical composition for steel grade B500B according to ASTM / AISI, satisfies both melts, and that there are no significant differences in the chemical composition of melts cast by different casting technologies of the same quality, given that primary and secondary technologies liquid steel treatments were the same.

\subsection{Analysis of non-metallic inclusions}

The analysis of non-metallic inclusions of the samples was performed using an optical microscope in the laboratory of ArcelorMittal Zenica. Results of analysis of non-metallic inclusions obtained in accordance with ISO 4967: 1998 (worst field method) for four tested melt samples, cast by open casting technology B500B - OC and for four tested melt samples, cast by closed casting technology B500B-CC.

Fig. 3 gives an overview of characteristic non-metallic inclusions on the samples of the finished product, ie. wires for melts that are cast without the application of stream protection, the so-called "open casting", steel designated B500B - OC, and for melts that are cast with the application of stream protection, the so-called "closed casting", steel designated B500B-CC [3].

a)

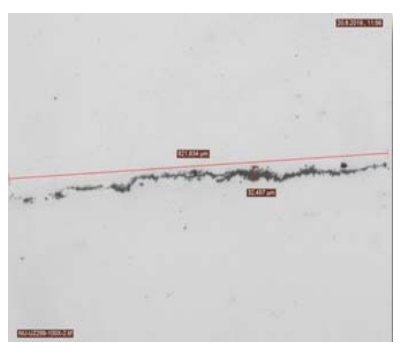

b)

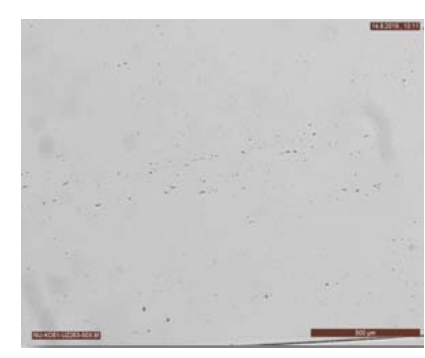

Fig. 3 Characteristic non-metallic inclusions for wire produced from melt a) by open casting of B500B-OC steel and b) by closed casting of B500B-CC steel, magnification $\times 100$

From the images obtained by the optical microscope, it could be concluded that in the steel wire marked B500B$\mathrm{OC}$, and from melts cast by open casting technology, the presence of non-metallic inclusions whose values exceed the values prescribed by ISO 4967: 1998, and that in most cases it is about complex inclusions of aluminates and silicates. In the case of B500B-CC steel wire produced by closed casting technology, no complex inclusions were observed as in the case of melts produced by open casting, and if non-metallic inclusions were present, they are much smaller in size, satisfying the sizes of nonmetallic inclusions prescribed by ISO 4967: 1998.

The diagrams, Figures 4 and 5, show the types and sizes of inclusions for steel wires designated B500B-OC and B500B-CC, which are cast by different casting technologies without and with the application of stream protection.

The application of closed casting technology results in a much smaller number of inclusions of the type: sulphides, aluminates, silicates and globular oxides. If inclusions are also present, they are smaller in size and length, and their sizes meet the values given by ISO 4967: 1998.

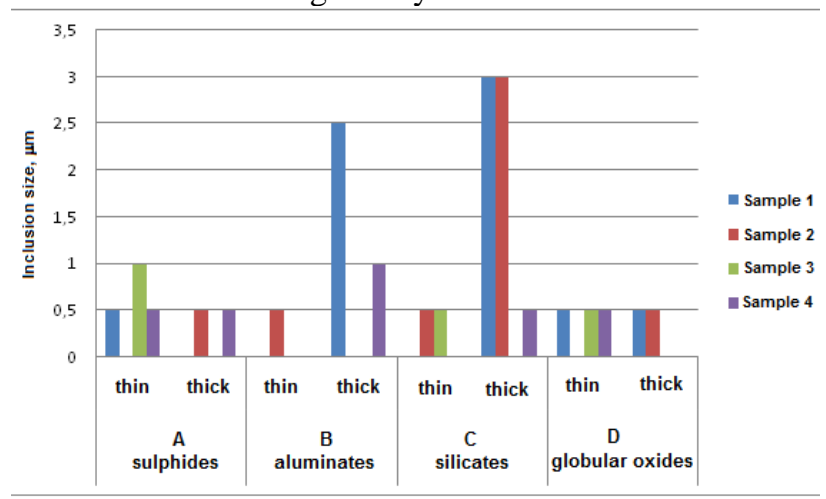

Fig. 4. Types and size of non-metallic inclusions of the four samples of steel designated B500B-OC [3]

A large number of thick and thin sulphides, aluminates, silicates and globular oxides were observed on wire samples produced from melts, which were cast by open casting. The worst field was observed in the sample of wire number 3 made of steel designated B500B-OC where also numerous of silicates is present, and complex thick aluminates, which exceed the value prescribed by ISO 4967: 1998.

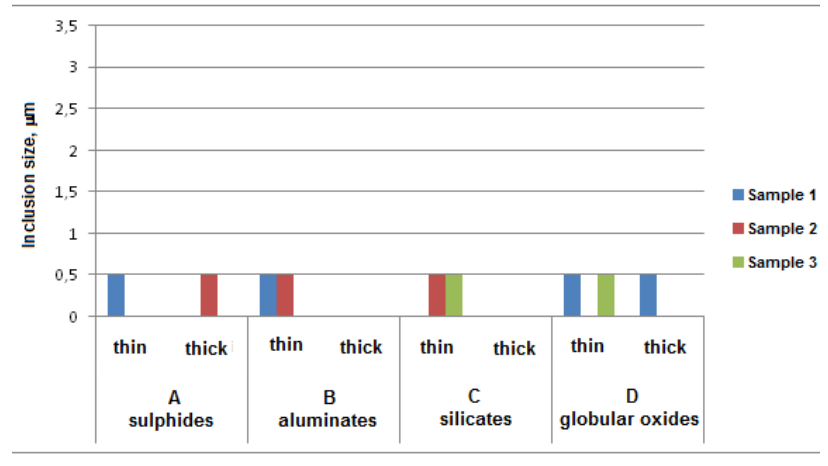

Fig. 5 Types and sizes of non-metallic inclusions of the three samples of steel designated B500B-CC [3]

The analysis of DS inclusions (globular oxide) in B500BOC steel wire revealed a higher number of DS inclusions in samples produced by open casting technology as opposed to melt samples produced by closed casting technology, in which a smaller number of DS inclusions are present and which they were also smaller in size.

In the case of melts produced by open casting technology (designation B500B-OC), non-metallic inclusions occurred in all samples exceeding the values prescribed by ISO 4967: 1998, while in the case of melts produced by closed casting technology (designation B500B-CC), a much smaller number of non-metallic inclusions was observed, which occurred in only three samples. Also, a higher presence of non-metallic inclusions was observed on samples from the melts produced by open casting technology than in samples from the melts produced by closed casting technology. From all the above, it can be concluded that in the case of the application of closed casting technology, a higher cleanness of steel in terms of 
non-metallic inclusions compared to open casting technology is achieved. All the improvements achieved in terms of steel cleanness significantly affect the mechanical properties of carbon steels and expand their application for the production of finished products.

\section{CONCLUSIONS}

Based on the obtained results, on a basis of on the conducted industrial research, from the aspect of changing the existing technology in the implementation of secondary metallurgy procedures with the application of stream protection, the degree of cleanness of carbon steels has improved, which also improves the mechanical properties of finished products. By analyzing the practical results led to the following conclusions:

- In the case of melts produced by open casting technology, the non-metallic inclusions that have appeared in all samples exceed the values prescribed by ISO 4967: 1998.

- A large number of thick and thin sulphides, aluminates, silicates and globular oxides were observed in melts produced by open casting technology.

- With the application of closed casting technology, a much smaller number of sulphides, aluminates, silicates and globular oxides appear.

The analysis of non-metallic inclusions steel melts designated B500B showed that the number of nonmetallic inclusions as well as the length of nonmetallic inclusions significantly reduced in the final product - wire produced from melts cast by closed casting technology in relation to wire produced from melts cast by open casting technology.

\section{REFERENCES}

[1] Costa e Silva A. (2019). The effects of nonmetallic inclusions on properties relevant to the performance of steel in structural and mechanical applications, Journal of Materials Research and Technology, Volume 8, Issue 2, April 2019, 24082422.

[2] Madias J., Moreno A. (2014). Strategies Against Reoxidation of Liquid Steel in Billet Casting with Metering Nozzle AISTech, 2014 Proceedings.

[3] Podojak A. (2020). Improving the treatment of secondary metallurgy in the production of carbon steels using closed casting technology, Magistar work, The Faculty of Metallurgy and Technology, University of Zenica.

\section{NOTE}

This paper is based on the paper presented at 5th International Conference on Mechanical Engineering Technologies and Applications - COMETa2020, organized by University of East Sarajevo, Faculty of Mechanical Engineering, East Sarajevo, Bosnia \& Herzegovina, 26 $6^{\text {th }}-28^{\text {th }}$ November, 2020. 